\title{
Effectiveness of training family physicians to deliver a brief intervention to address excessive substance use among young patients: a cluster randomized controlled trial
}

\author{
Dagmar M. Haller MD, Anne Meynard MD, Daniele Lefebvre MD, Obioha C. Ukoumunne PhD, \\ Françoise Narring MD, Barbara Broers MD
}

See related commentary by Levy at www.cmaj.ca/lookup/doi/10.1503/cmaj.140303

\section{- ABSTRACT}

Background: Brief interventions delivered by family physicians to address excessive alcohol use among adult patients are effective. We conducted a study to determine whether such an intervention would be similarly effective in reducing binge drinking and excessive cannabis use among young people.

Methods: We conducted a cluster randomized controlled trial involving 33 family physicians in Switzerland. Physicians in the intervention group received training in delivering a brief intervention to young people during the consultation in addition to usual care. Physicians in the control group delivered usual care only. Consecutive patients aged 15-24 years were recruited from each practice and, before the consultation, completed a confidential questionnaire about their general health and substance use. Patients were followed up at 3, 6 and 12 months after the consultation. The primary outcome measure was self-reported excessive substance use $(\geq 1$ episode of binge drinking, or $\geq 1$ joint of cannabis per week, or both) in the past 30 days.

Results: Of the 33 participating physicians, 17 were randomly allocated to the intervention group and 16 to the control group. Of the 594 participating patients, 279 (47.0\%) identified themselves as binge drinkers or excessive cannabis users, or both, at baseline. Excessive substance use did not differ significantly between patients whose physicians were in the intervention group and those whose physicians were in the control group at any of the follow-up points (odds ratio [OR] and $95 \%$ confidence interval $[\mathrm{Cl}]$ at 3 months: 0.9 [0.6-1.4]; at $6 \mathrm{mo}: 1.0$ [0.6-1.6]; and at 12 mo: 1.1 [0.7-1.8]). The differences between groups were also nonsignificant after we restricted the analysis to patients who reported excessive substance use at baseline (OR 1.6, 95\% Cl 0.9-2.8, at 3 mo; OR 1.7, 95\% $\mathrm{Cl} 0.9-3.2$, at $6 \mathrm{mo}$; and OR 1.9, 95\% Cl 0.94.0 , at $12 \mathrm{mo}$ ).

Interpretation: Training family physicians to use a brief intervention to address excessive substance use among young people was not effective in reducing binge drinking and excessive cannabis use in this patient population. Trial registration: Australian New Zealand Clinical Trials Registry, no. ACTRN12608000432314.
$\mathrm{M}$ ost health-compromising behaviours begin in adolescence. ${ }^{1}$ Interventions to address these behaviours early are likely to bring long-lasting benefits. ${ }^{2}$ Harmful use of alcohol is a leading factor associated with premature death and disability worldwide, with a disproportionally high impact on young people (aged 10-24 yr). ${ }^{3.4}$ Similarly, early cannabis use can have adverse consequences that extend into adulthood. ${ }^{5-8}$

In adolescence and early adulthood, binge drinking on at least a monthly basis is associated with an increased risk of adverse outcomes later in life. ${ }^{9-12}$ Although any cannabis use is potentially harmful, weekly use represents a threshold in adolescence related to an increased risk of cannabis (and tobacco) dependence in adulthood. ${ }^{13}$ Binge drinking affects $30 \%-50 \%$ and excessive cannabis use about $10 \%$ of the adolescent and young adult population in Europe and the United States..$^{10,14,15}$

Reducing substance-related harm involves multisectoral approaches, including promotion of healthy child and adolescent development, regulatory policies and early treatment interventions. ${ }^{16}$ Family physicians can add to the public health messages by personalizing their content within brief interventions. ${ }^{17,18}$ There is evidence that brief interventions can encourage young people to reduce substance use, yet most studies have been conducted in community settings (mainly educational), emergency services or specialized addic-
Competing interests: None declared.

This article has been peer reviewed.

Correspondence to:

Dagmar Haller, dagmar .haller-hester@hcuge.ch

CMAJ 2014. DOI:10.1503 /cmaj.131301 
tion clinics. ${ }^{1.16}$ Studies aimed at adult populations have shown favourable effects of brief alcohol interventions, and to some extent brief cannabis interventions, in primary care. ${ }^{19-22}$ These interventions have been recommended for adolescent populations. ${ }^{4,5,16}$ Yet young people have different modes of substance use and communication styles that may limit the extent to which evidence from adult studies can apply to them.

Recently, a systematic review of brief interventions to reduce alcohol use in adolescents identified only 1 randomized controlled trial in primary care. ${ }^{23}$ The tested intervention, not provided by family physicians but involving audio self-assessment, was ineffective in reducing alcohol use in exposed adolescents. ${ }^{24}$ Sanci and colleagues showed that training family physicians to address health-risk behaviours among adolescents was effective in improving provider performance, but the extent to which this translates into improved outcomes remains unknown. ${ }^{25,26}$ Two nonrandomized studies suggested screening for substance use and brief advice by family physicians could favour reduced alcohol and cannabis use among adolescents, ${ }^{27,28}$ but evidence from randomized trials is lacking. ${ }^{29}$

We conducted the PRISM-Ado (Primary care Intervention Addressing Substance Misuse in Adolescents) trial, a cluster randomized controlled trial of the effectiveness of training family physicians to deliver a brief intervention to address binge drinking and excessive cannabis use among young people.

\section{Methods}

\section{Study design and setting}

Our pilot study informed all methods for this trial. ${ }^{30} \mathrm{We}$ designed a cluster randomized controlled trial to be conducted in family medicine practices in the French-speaking part of Switzerland (in Switzerland, these practitioners also include general internists and pediatricians). Randomization was done at the practice level, because contamination between groups might otherwise have occurred had patients been randomized.

The study protocol was approved by the Ethics Committee for Studies in Outpatient Care (protocol 08-28).

\section{Physician recruitment and randomization}

A letter was sent to all physicians on the mailing lists for continuing medical education of the departments of family medicine at the University of Geneva and the University of Lausanne, and to all pediatricians in private practice in the Canton of Geneva, for a total of about 1200 doctors serving a population of approximately 1.2 million people. Of the first 35 physicians who expressed interest, 33 (including 5 pediatricians) from as many practices consented and were randomly allocated to the intervention and control groups.

An independent statistician (provided only with identifying numbers for the practices) who was not otherwise connected with the trial performed the randomization of the practices in a single batch using computer-generated random numbers. The study coordinator matched the allocation list and informed the physicians, but not the practice assistant, of their group status. Research assistants who conducted follow-up interviews and researchers involved in the data analysis were unaware of the group allocations.

\section{Patient recruitment}

In each participating practice, the practice assistant recruited young people consulting for any health problem. We defined young people as those aged 10-24 years, according to the World Health Organization's definition. ${ }^{2}$ To preserve the confidentiality of the medical encounter for anyone consulting without his or her parents, we restricted recruitment to patients who could give their own consent to participate (age 15-24 years). ${ }^{31,32}$

We excluded patients who had acute illness requiring immediate attention, severe mental disorder, substance abuse requiring more immediate attention (e.g., recent court ruling regarding drunk driving), previous treatment for dependence, inability to read and understand French, or any other disorder affecting the person's capacity to consent. If in doubt as to the person's capacity to consent, the practice assistant requested advice from the physician.

Although we could not conceal trial arm allocation from the physicians, we did conceal it from the patients (they were told they were participating in a study of their health and substance use).

\section{Baseline patient survey}

Before the consultation, participating patients were invited to complete a survey evaluating their general health, substance use, and sociodemographic and psychosocial status. Questions about substance use were taken from the DEP-ADO clinical questionnaire, a validated screening instrument in French that asks about frequency of use (for which self-report has previously been shown to be reliable) and psychosocial consequences related to alcohol and cannabis use. ${ }^{33,34}$

Young people involved in our pilot study had reported that they would be less likely to respond honestly if the baseline survey were to be used in the consultation. Thus, the baseline surveys were collected in sealed envelopes before the consul- 
tation and not made available to the physicians to help them identify patients at risk. ${ }^{30}$ As a result, all young people who consented to participate were included in the trial, not only those who reported excessive substance use at baseline.

Participants were asked to provide 2 contact numbers (mobile phone numbers, if possible; the second one could be their parent's or sibling's, for example) to allow follow-up assessments at 3, 6 and 12 months after the initial consultation.

\section{Intervention}

Physicians allocated to the intervention arm participated in groups of 4 in two interactive training sessions (Box 1). The training sessions were designed by 2 of us (D.M.H. and A.M., both family physicians trained in adolescent health; A.M. is also a trainer in motivational interviewing) and were built upon the evidence for effective medical education in adolescent health. ${ }^{26,35}$

The brief intervention followed the principles for successful interventions with young people. ${ }^{16}$ It involved a motivational interviewing style ${ }^{36}$ and the $5 \mathrm{As}$ framework ${ }^{37}$ to discuss behaviour change. The intervention was developed by the pilot team (the research team in collaboration with the 10 family physicians who formed the advisory group in the pilot study).$^{30}$ We chose the 5As framework because it proposes a structure to provide key elements associated with successful brief interventions, such as personalized feedback and setting of goals. ${ }^{38}$

The pilot team created a checklist that was used by practitioners both to support them in delivering the intervention and to monitor how they delivered it (Figure 1). The pilot study in 7 practices was successful in showing that the intervention could be used during the consultation to address binge drinking and excessive cannabis use. $^{30}$ The reduction in the proportion of excessive substance users 1 month after exposure to the brief intervention in the pilot practices, consistent with that reported in trials involving adults, ${ }^{20}$ provided support for the validity of our approach. ${ }^{30}$

During the training, the practitioners were instructed to go through some or all of the $5 \mathrm{As}$ depending on their assessment of the patient's need and motivation to change. They used the checklist to guide their intervention and to record which steps they had performed for each patient. The small-group format during the training sessions (a trainer, an adolescent actor as a simulated patient and 4 participating physicians) allowed direct observation, feedback and suggestions by co-participants to monitor and improve adherence to the brief intervention. Participants were advised to practise at least twice, before and after receiving feedback, to maximize their skills. Because the checklist was to be used to prompt and monitor physicians' adherence to the brief intervention during the trial, particular emphasis was placed on the correct use of the form. To screen for substance use (the first of the 5As), physicians were advised to ask about frequency and type of use in a nonjudgmental way. They were not given a screening tool to use, because existing tools were either too long to be used for opportunistic screening or had not been validated for use in French. ${ }^{34,39,40}$ The physicians received continuing medical education credits but no financial incentive for participating in the training sessions.

All patients were first offered usual care. Patients recruited in the intervention practices were offered the brief intervention in addition to usual care.

In both groups, physicians were free to plan follow-up consultations to further discuss substance use with the patient. To minimize reporting-related bias, we chose not to collect any information about these follow-up plans.

\section{Outcome measures}

The primary outcome measure was self-reported excessive alcohol or cannabis use in the past 30 days. Outcomes were measured by the research assistants through telephone interviews with the patients at 3, 6 and 12 months after the consulta-

\section{Box 1: Summarized description of the training intervention}

\section{Session 1}

- Duration $3 \mathrm{~h}$

- Interactive session with quizzes and group exercises

- Participants were given information on the epidemiology of substance use in young people and an introduction to a motivational communication style appropriate for this age group

- Adolescent actors were used as simulated patients to help participants practise how to discuss substance use when young people consult them because of common medical problems (e.g., ankle sprain, check-up)

- Participants performed exercises with the simulated patients, practising the delivery of the brief intervention using the motivational interviewing style and the 5As framework (Figure 1) to address substance use

- The actors provided personalized feedback to the participants

\section{Session 2}

- Duration $2 \mathrm{~h}$; held 10-15 d after the first session

- The training session was provided to participants in groups of 3 or 4 in one of the participants' own practices; physicians practised delivering the brief intervention in consultations with a simulated patient in a "natural environment"

- Trainers monitored the participants' adherence to the intervention

- The simulated patients gave personalized feedback to the physicians and comments on the entire research process (on completing the baseline survey in the waiting room, the consultation and the brief intervention)

All participants received a portfolio containing a summary of items discussed during the training sessions, additional reading material, and a list of resources in the local health network for referring patients or obtaining expert advice. 
tion. Excessive use was defined as at least 1 episode of binge drinking for alcohol and at least 1 joint per week for cannabis (based on thresholds for increased risk of adverse outcomes identified in cohort studies $\left.{ }^{1-13}\right)$. The respective questions were: "In the past 30 days, how many times did you have 5 drinks of alcohol or more on the same occasion?" and "In the past 30 days, did you use cannabis? If so, how often? (Approximately once; on weekends or once or twice during the week; three times or more a week but not every day; or every day)". We also measured abstinence from alcohol and cannabis, and psychosocial consequences of alcohol and cannabis use from 9 possibilities listed in the DEP-ADO questionnaire. ${ }^{34}$

\section{Statistical analysis}

We calculated the sample size to detect a $15 \%$ reduction from baseline in the proportion of patients reporting excessive substance use in the intervention group compared with no reduction in the control group, with $80 \%$ power at the $5 \%$ level of significance. Because substance use in adolescence increases with age, we anticipated no reduction in use in the control group. ${ }^{41}$ The target reduction is relevant from a clinical and public health perspective and is in line with results from trials involving adults. ${ }^{20}$ Ignoring clustering effects, we estimated that 60 patients reporting excessive substance use would be required in each trial arm. Estimating that about $35 \%$ of participants would report excessive substance use at baseline (the

\begin{tabular}{|c|c|c|}
\hline \multicolumn{3}{|c|}{$\begin{array}{l}\text { Doctor ID : } \\
\text { Patient code : }\end{array}$} \\
\hline STEP & CONTENT & DONE $(\sqrt{ })$ \\
\hline ASSESS & $\begin{array}{l}\text { - Frequency and circumstances of use? } \\
\text { - Psychosocial problems in relation to substance use? } \\
\text { - Does alcohol or cannabis use affect the young person's health at the moment? }\end{array}$ & \\
\hline ADVISE & $\begin{array}{l}\text { - Does the young person have questions about the possible effects of his/her use on } \\
\text { his/her health? } \\
\text { - Provide personalized information taking into account the medico-psycho-social } \\
\text { problems the young person reports and his/her questions }\end{array}$ & \\
\hline AGREE & $\begin{array}{l}\text { - Intention to change on a scale of } 0 \text { to } 10 \text { ? } \\
\text { - What type of changes does the young person consider undertaking? } \\
\text { - Agree on a realistic objective for the young person and a time frame for its completion }\end{array}$ & \\
\hline ASSIST & $\begin{array}{l}\text { - Identify potential "lost benefits" in changing behaviour and ways of compensating } \\
\text { for them } \\
\text { - Discuss ways of reaching objectives (e.g., initiating a change together with peers, } \\
\text { "a bet") } \\
\text { - Agree on a plan for action }\end{array}$ & \\
\hline ARRANGE & $\begin{array}{l}\text { - Give documents to the young person and the website address www.ciao.ch } \\
\text { - Propose ways in which the young person could communicate to you his/her potential } \\
\text { success in changing }\end{array}$ & \\
\hline
\end{tabular}

$>\quad$ In your view, does this young person currently present with excessive substance use?

$\begin{array}{cccc}\text { of alcohol } & \text { Yes } \square 1 & \text { of cannabis } & \text { Yes } \\ \text { No } & \square 0 & & \square \\ & & \text { No } & \square 0\end{array}$

$>$ Duration of the intervention

\begin{tabular}{|l|l|}
\hline & $\leq 5$ minutes \\
\hline & $6-10$ minutes \\
\hline & $11-15$ minutes \\
\hline & $\geq 15$ minutes \\
\hline
\end{tabular}

Figure 1: Checklist and report form used by the participating family physicians when delivering the brief intervention. The form includes the main components of the 5As framework for the brief intervention, as described by Marlow and Stoller. ${ }^{37}$ [Original form was in French.] 
baseline prevalence in our pilot study), ${ }^{30}$ we needed to recruit 170 participants per arm. To adjust for clustering, we anticipated that we would recruit 25 participants from each practice and assumed an intracluster (intrapractice) correlation coefficient of $0.03 . .^{30,42}$ We further assumed a $20 \%$ loss to followup at the participant level (thus basing the design effect on 20 patients per cluster). Including an extra 3 clusters in each trial arm to allow for inefficiency due to variability in the number of patients per cluster and dropout at the cluster level, we required a sample size of 20 patients (including 7 who were excessive substance users) from each of the 15 practices in each trial group.

We used the intention-to-treat principle to compare outcomes between the groups, with patients analyzed according to the group to which their physician was randomly allocated. Marginal logistic regression models using generalized estimating equations (GEE) with information sandwich ("robust") estimates of standard error were fitted to compare the binary outcomes between the trial arms. An exchangeable correlation structure was specified for the GEE analyses. This method allows for the correlation of patient outcomes within clusters. Because all patients had potentially been exposed to the brief intervention regardless of their self-reported level of substance use, we first ran the analyses for the entire sample and then restricted it to those who reported binge drinking or excessive cannabis use at baseline. We ran the models with all available data initially and then conducted sensitivity analyses to check the stability of our findings when missing data were replaced using last observation carried forward. We used Stata software to analyze the data.

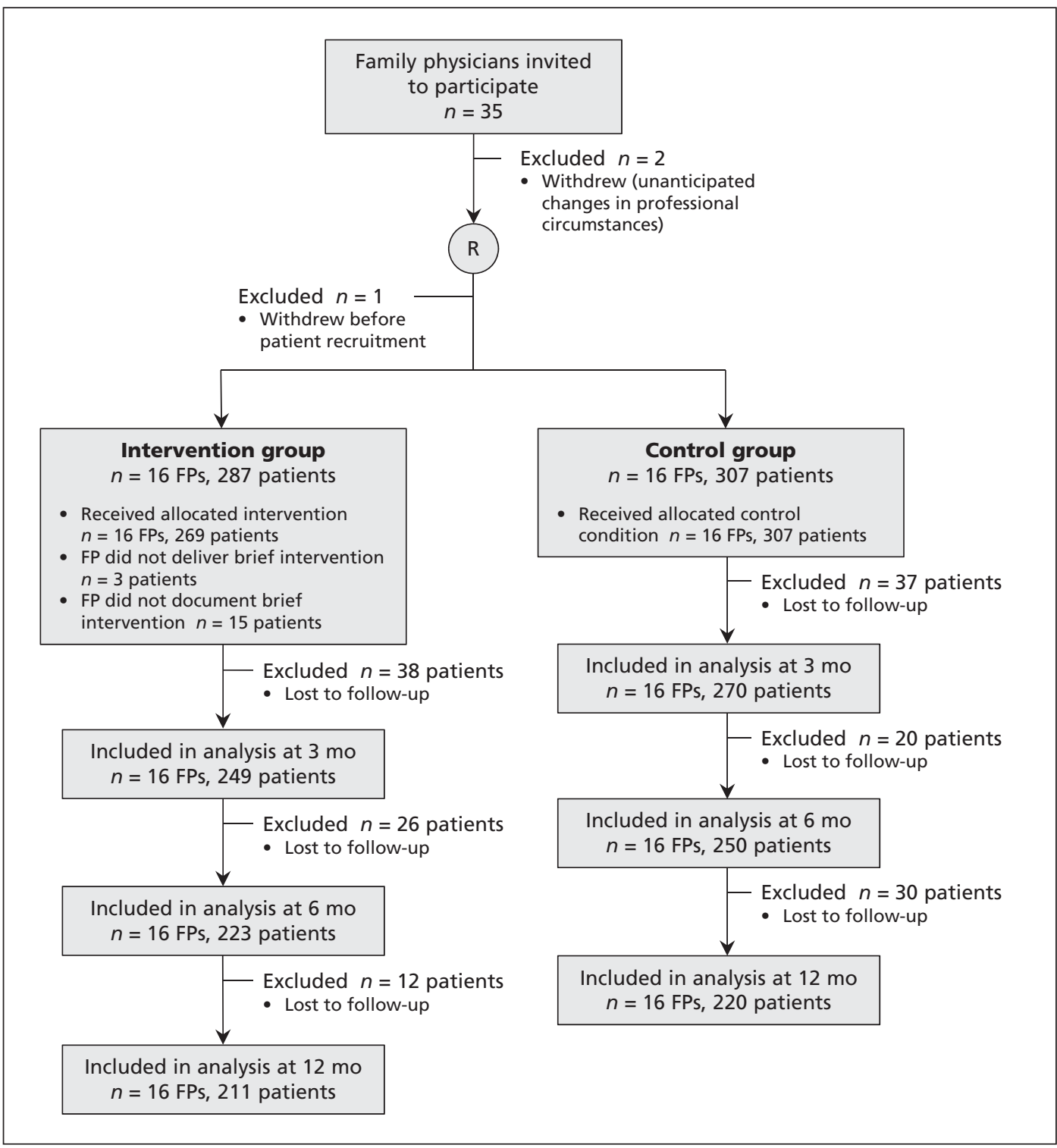

Figure 2: Flow of participants through the trial. FP = family physician (in Switzerland, family medicine practitioners also include general internists and pediatricians), $R=$ randomization. 
Table 1: Characteristics of family physicians included in the trial

\begin{tabular}{|c|c|c|}
\hline \multirow[b]{2}{*}{ Characteristic } & \multicolumn{2}{|c|}{ Group; no. (\%) of physicians* } \\
\hline & $\begin{array}{c}\text { Intervention } \\
n=17 t\end{array}$ & $\begin{array}{c}\text { Control } \\
n=16\end{array}$ \\
\hline \multicolumn{3}{|l|}{ Age group, yr } \\
\hline $36-45$ & $8(47)$ & $8(50)$ \\
\hline $46-55$ & $8(47)$ & $4(25)$ \\
\hline$>55$ & $1(6)$ & $4(25)$ \\
\hline Sex, male & $8(47)$ & $11(69)$ \\
\hline Specialty in pediatrics $\ddagger$ & $3(18)$ & $2(12)$ \\
\hline No. of years in private practice, mean \pm SD & $13.7 \pm 2.3$ & $9.2 \pm 1.7$ \\
\hline Practice located in urban area, \% & $12(71)$ & $10(62)$ \\
\hline \multicolumn{3}{|l|}{$\begin{array}{l}\text { Moderate to extensive training (> } 10 \mathrm{~h}) \\
\text { in topic before the study§ }\end{array}$} \\
\hline Adolescent health & $6(35)$ & $12(75)$ \\
\hline Communication & $5(29)$ & $8(50)$ \\
\hline Motivational interviewing & $7(54)$ & $7(44)$ \\
\hline Alcohol problems & $10(59)$ & $11(69)$ \\
\hline Cannabis problems & $5(29)$ & $6(38)$ \\
\hline \multicolumn{3}{|c|}{$\begin{array}{l}\text { Note: SD = standard deviation. } \\
\text { *Unless stated otherwise. } \\
\text { tOne physician dropped out of the study after randomization, before patient recruitment began. } \\
\text { \#In Switzerland, family medicine practitioners also include general internists and pediatricians. } \\
\text { SPhysicians' estimates (includes formal and informal training); data partially missing for } 4 \text { physicians }\end{array}$} \\
\hline
\end{tabular}

Table 2: Characteristics of patients who participated in the trial, by group to which their physician was allocated

\begin{tabular}{|c|c|c|}
\hline \multirow[b]{2}{*}{ Characteristic } & \multicolumn{2}{|c|}{ Group; no. (\%) of patients* } \\
\hline & $\begin{array}{l}\text { Intervention } \\
\quad n=287\end{array}$ & $\begin{array}{l}\text { Control } \\
n=307\end{array}$ \\
\hline Age, yr, mean \pm SD & $18.4 \pm 2.5$ & $18.6 \pm 2.7$ \\
\hline Sex, male & $140(48.8)$ & $138(45.0)$ \\
\hline Student & $159(55.4)$ & $169(55.0)$ \\
\hline $\begin{array}{l}\text { Self-assessed health rated as excellent } \\
\text { or very good }\end{array}$ & $162(56.4)$ & $167(54.4)$ \\
\hline No. of lifetime sexual partners, median (IQR) & $1(0-4)$ & $1(0-4)$ \\
\hline Daily tobacco use & $72(25.1)$ & $65(21.2)$ \\
\hline \multicolumn{3}{|l|}{ Alcohol use } \\
\hline None & $73(25.4)$ & $72(23.5)$ \\
\hline $\begin{array}{l}\text { No. of episodes of binge drinking in past } \\
12 \text { mo, median (IQR) }\end{array}$ & $2(0-9)$ & $2(0-9)$ \\
\hline $\begin{array}{l}\text { Excessive use ( } \geq 1 \text { episode of binge drinking } \\
\text { in past } 30 \mathrm{~d} \text { ) }\end{array}$ & $114(39.7)$ & $142(46.3)$ \\
\hline $\begin{array}{l}\text { High-risk binge drinking ( } \geq 2 \text { episodes } \\
\text { in past } 30 \mathrm{~d} \text { ) }\end{array}$ & $74(25.8)$ & $90(29.3)$ \\
\hline \multicolumn{3}{|l|}{ Cannabis use } \\
\hline None & $219(76.3)$ & $257(83.7)$ \\
\hline Excessive use ( $\geq 1$ joint per $w k$ ) & $36(12.5)$ & $29(9.4)$ \\
\hline $\begin{array}{l}\text { Any excessive substance use (cannabis, } \\
\text { alcohol or both) }\end{array}$ & $130(45.3)$ & $149(48.5)$ \\
\hline $\begin{array}{l}\text { Note: IQR = interquartile range, SD = standard deviation. } \\
\text { *Unless stated otherwise. }\end{array}$ & & \\
\hline
\end{tabular}

\section{Results}

\section{Physician and patient characteristics}

The recruitment process is summarized in Figure 2. Of the 33 physicians who agreed to participate, 1 withdrew after group allocation but before patient recruitment. The 16 physicians in the intervention group attended both training sessions. The characteristics of the 33 physicians are presented in Table 1. Most of the physicians had moderate to extensive training in adolescent health and alcoholrelated problems before the study.

A total of 636 patients were eligible to participate in the 32 practices between February 2009 and November 2010. Of these, 40 declined participation and 2 did not complete the baseline survey, for a $93.4 \%$ participation rate. Of the 594 participating patients, $279(47.0 \%)$ reported binge drinking, excessive cannabis use or both. There were no marked differences between the 2 groups in patient characteristics at baseline (Table 2).

Follow-up rates at 3, 6 and 12 months were $87 \%, 80 \%$ and $73 \%$, respectively, and were similar in each arm. Patients lost to follow-up did not differ significantly between the study groups in number, mean age or substance use; they were more likely than patients not lost to follow-up to be male ( $57 \%$ v. $43 \%)$.

The most frequently reported reasons for consulting the family physician were health maintenance/check-up, acute upper respiratory tract infection, depressive symptoms, limb trauma and acne. Four patients consulted the physician because of a substance abuse problem.

\section{Excessive substance use at follow-up}

Excessive substance use reported at 3,6 and 12 months after the brief intervention are reported for the entire sample (Table 3) and for the subgroup who reported excessive substance use at baseline (Table 4). Overall, 27.8\% (55/198) of the patients who reported excessive use at baseline indicated that they were no longer excessive substance users at 12 months' follow-up.

The odds of binge drinking or excessive cannabis use, or both, did not differ significantly between the study groups, nor did the secondary outcomes (Tables 3 and 4). Sensitivity analyses using last observation carried forward to account for missing data at follow-up resulted in similar findings.

\section{Family physicians' experience}

Table 5 shows the physicians' experience using the brief intervention and the sensitivity of their identification of excessive substance use. All but 3 patients were screened for substance use (the first step in the 5As framework). Most of the patients 
(66.2\% overall and $80.6 \%$ of those who reported excessive substance use at baseline) were exposed to at least 2 steps of the 5As framework. Physicians spent more time administering the intervention (6-10 $\mathrm{min}$ ) and went through more steps with patients in whom they identified excessive substance use, although the sensitivity of their identification of excessive substance use was low, particularly for binge drinking (Table 5).

\section{Interpretation}

Training family physicians to deliver a brief intervention to address excessive substance use failed to reduce binge drinking and excessive cannabis use among young patients at 3,6 and 12 months follow-up, as compared with the control group providing usual care during consultations. Overall, however, we noted a $28 \%$ reduction in the proportion of patients reporting excessive substance use at 12 months. Formal training in using the brief intervention may only have had a modest impact on the ability of experienced and interested family physicians to adapt their communication style with young people. Improved outcomes in both groups may also have been due to the patients completing the baseline survey. ${ }^{43}$ This step in the study protocol may have encouraged the patients who were already primed through public health and educational messages to identify a personal need for change.

To reproduce real-life conditions (and because of the absence of suitable validated instruments for primary care in French), no formal screening tools

Table 3: Excessive substance use, abstinence and psychosocial consequences* among all participating patients $(n=594)$

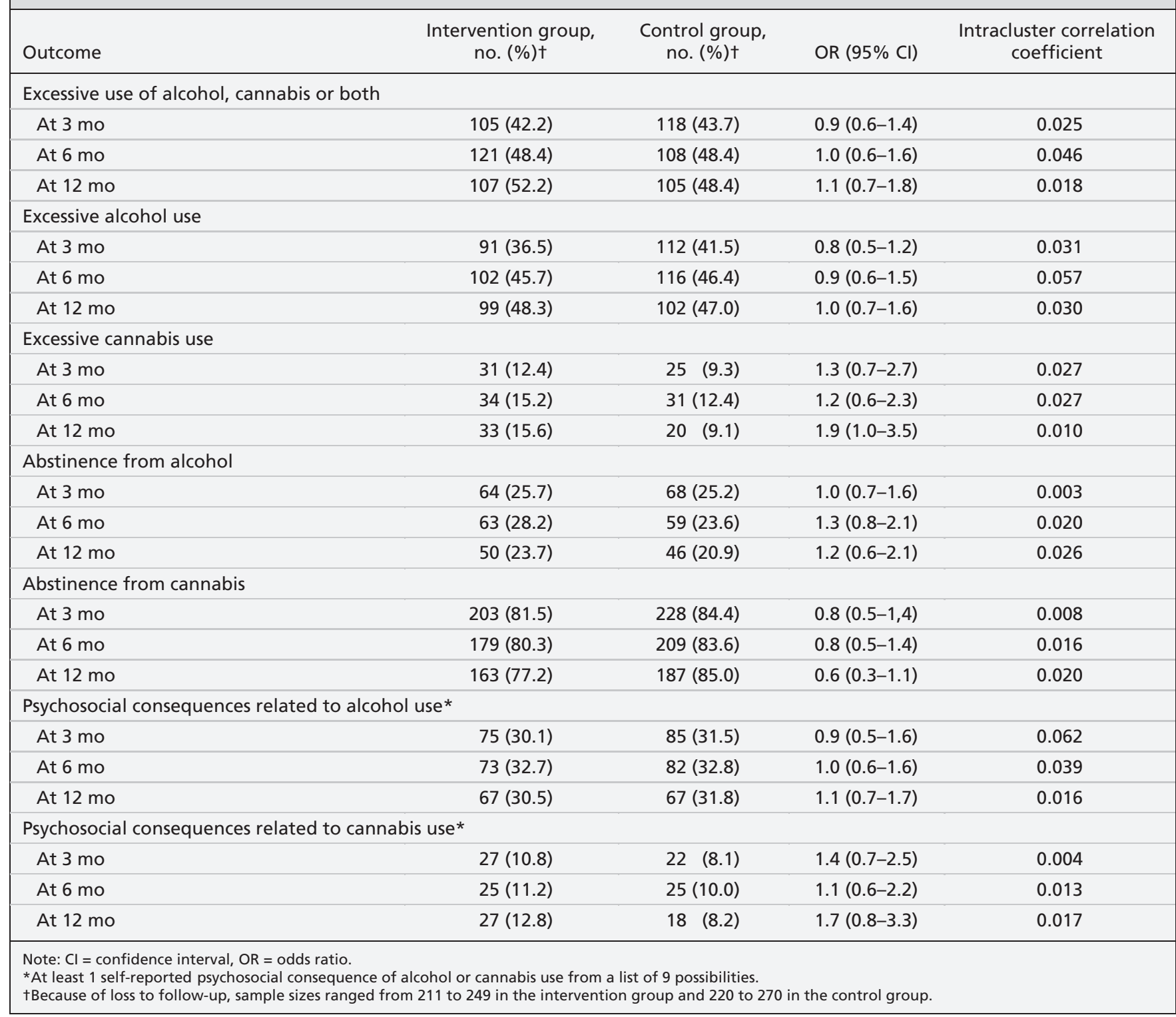


Table 4: Excessive substance use, abstinence and psychosocial consequences* among patients who reported excessive substance use at baseline $(n=279)$

\begin{tabular}{|c|c|c|c|c|}
\hline Outcome & $\begin{array}{c}\text { Intervention group, } \\
\text { no. }(\%) \dagger\end{array}$ & $\begin{array}{c}\text { Control group, } \\
\text { no. }(\%) \dagger\end{array}$ & OR $(95 \% \mathrm{Cl})$ & $\begin{array}{c}\text { Intracluster correlation } \\
\text { coefficient }\end{array}$ \\
\hline \multicolumn{5}{|c|}{ Excessive use of alcohol, cannabis or both } \\
\hline At 3 mo & $82(73.9)$ & $85(64.9)$ & $1.6(0.9-2.8)$ & 0.022 \\
\hline At $6 \mathrm{mo}$ & $77(76.2)$ & $78(65.0)$ & $1.7(0.9-3.2)$ & 0.003 \\
\hline At $12 \mathrm{mo}$ & 75 (78.9) & $68(66.0)$ & $1.9(0.9-4.0)$ & 0.029 \\
\hline \multicolumn{5}{|c|}{ Excessive alcohol use } \\
\hline At $3 \mathrm{mo}$ & $79(60.3)$ & $69(62.2)$ & $1.1(0.6-2.0)$ & 0.058 \\
\hline At 6 mo & $72(71.3)$ & $73(60.8)$ & $1.4(0.7-2.8)$ & 0.052 \\
\hline At $12 \mathrm{mo}$ & $70(73.7)$ & $65(63.1)$ & $1.6(0.7-3.5)$ & 0.083 \\
\hline \multicolumn{5}{|c|}{ Excessive cannabis use } \\
\hline At $3 \mathrm{mo}$ & $30(27.0)$ & $24(18.3)$ & $1.6(0.8-3.4)$ & 0.052 \\
\hline At $6 \mathrm{mo}$ & $29(28.7)$ & $28(23.3)$ & $1.3(0.6-2.5)$ & 0.028 \\
\hline At $12 \mathrm{mo}$ & $28(29.2)$ & $18(17.3)$ & $2.1(1.0-4.4)$ & 0.034 \\
\hline \multicolumn{5}{|c|}{ Abstinence from alcohol } \\
\hline At 3 mo & $8(7.2)$ & $13(9.9)$ & $0.7(0.3-1.8)$ & 0.003 \\
\hline At 6 mo & $12(10.0)$ & $11(10.9)$ & $1.2(0.5-3.2)$ & 0.041 \\
\hline At $12 \mathrm{mo}$ & $12(12.5)$ & $6(5.8)$ & $2.5(0.9-7.4)$ & 0.033 \\
\hline \multicolumn{5}{|c|}{ Abstinence from cannabis } \\
\hline At $3 \mathrm{mo}$ & $72(64.9)$ & $97(74.0)$ & $0.7(0.4-1.2)$ & 0.003 \\
\hline At 6 mo & $65(64.4)$ & $87(72.5)$ & $0.7(0.4-1.3)$ & 0.013 \\
\hline At $12 \mathrm{mo}$ & $57(59.4)$ & $77(74.0)$ & $0.5(0.2-1.0)$ & 0.033 \\
\hline \multicolumn{5}{|c|}{ Psychosocial consequences related to alcohol use* } \\
\hline At $3 \mathrm{mo}$ & $52(46.9)$ & $58(44.3)$ & $1.1(0.6-1.9)$ & 0.065 \\
\hline At 6 mo & $49(48.5)$ & $52(43.3)$ & $1.2(0.6-2.3)$ & 0.115 \\
\hline At $12 \mathrm{mo}$ & $45(46.9)$ & $47(45.2)$ & $1.1(0.6-1.8)$ & 0.000 \\
\hline \multicolumn{5}{|c|}{ Psychosocial consequences related to cannabis use* } \\
\hline At 3 mo & $26(23.4)$ & $20(15.3)$ & $1.7(1.0-3.1)$ & 0.000 \\
\hline At $6 \mathrm{mo}$ & $21(20.8)$ & $21(17.5)$ & $1.2(0.5-2.6)$ & 0.027 \\
\hline At $12 \mathrm{mo}$ & $23(24.0)$ & $15(14.4)$ & $1.9(0.9-4.3)$ & 0.034 \\
\hline
\end{tabular}

were used by the physicians. This may have affected their identification of excessive substance use. Young people may choose to minimize the report of their level of use in the consultation depending on their wish to further discuss this with their physician..$^{30}$ This would imply that a stronger emphasis on "youth-friendly" screening is necessary, and possibly follow-up calls or consultations.

\section{Limitations}

Participating physicians had a special interest in the theme and therefore may not be considered entirely representative of the average population of family physicians. Most reported some experience in adolescent health and were used to addressing excessive alcohol use in adults. Their interest was in learning to apply these concepts with young people. To stay close to real-life conditions, we collected only indirect (self-reported) information on how the physicians conducted the brief intervention and did not ask for information on follow-up appointments. However, the correct use of the checklist was promoted and monitored during training. According to these reports, most of the patients were screened for substance use and exposed to at least 2 of the 5 elements of the brief intervention.

\section{Implications for future research}

The negative results of our trial do not undermine a possible role for family physicians in modifying substance use behaviours in adoles- 
Table 5: Self-reported use of brief intervention by physicians in intervention group and sensitivity in identifying excessive substance use

\begin{tabular}{|c|c|c|c|}
\hline Variable & $\begin{array}{c}\text { All patients, } \\
\text { no. }(\%) \\
n=272^{*}\end{array}$ & $\begin{array}{c}\text { Patients reporting } \\
\text { excessive substance } \\
\text { use, no. }(\%) \\
n=124 \dagger\end{array}$ & $\begin{array}{l}\text { Patients with excessive } \\
\text { substance use } \\
\text { according to FP, no. (\%) } \\
n=51\end{array}$ \\
\hline \multicolumn{4}{|c|}{$\begin{array}{l}\text { Time spent administering brief } \\
\text { intervention with each patient, min }\end{array}$} \\
\hline$\leq 5$ & $150(57.0)$ & $50(40.2)$ & $9 \quad(18.0)$ \\
\hline $6-10$ & $90(34.2)$ & 57 (45.9) & $28 \quad(55.0)$ \\
\hline $10-15$ & $15 \quad(5.7)$ & $11(9.0)$ & $8 \quad(16.0)$ \\
\hline$>15$ & $8 \quad(3.0)$ & $6 \quad(4.9)$ & $5 \quad(10.0)$ \\
\hline $\begin{array}{l}\text { FP screened for substance use } \\
\text { (first of } 5 \mathrm{As} \text { ) }\end{array}$ & 269 (98.9)§ & $123(99.2)$ & $51(100.0)$ \\
\hline \multicolumn{4}{|l|}{$\begin{array}{l}\text { No. of steps in } 5 \text { As framework } \\
\text { FP reported doing }\end{array}$} \\
\hline None & $3(1.1)$ & $1 \quad(0.8)$ & 0 \\
\hline 1 & $89(32.7)$ & $22(17.7)$ & $5 \quad(9.8)$ \\
\hline 2 & $96(35.3)$ & $46(37.1)$ & 9 (17.6) \\
\hline 3 & $41(15.1)$ & $19(15.3)$ & 9 (17.6) \\
\hline 4 & $24 \quad(8.8)$ & $22(17.7)$ & 17 (33.3) \\
\hline 5 & $19(7.0)$ & $13(10.5)$ & 11 (21.6) \\
\hline $\begin{array}{l}\text { Sensitivity of FPs' identification } \\
\text { of binge drinking, } \% \neq\end{array}$ & NA & NA & 33.6 \\
\hline $\begin{array}{l}\text { Sensitivity of FPs' identification } \\
\text { of excessive cannabis use, } \% \ddagger\end{array}$ & NA & NA & 59.4 \\
\hline \multicolumn{4}{|c|}{$\begin{array}{l}\text { Note: } F P \text { = family physician (in Switzerland, family medicine practitioners also include general internists and pediatricians), NA = } \\
\text { not applicable. } \\
\text { *Data missing for } 15 \text { patients. } \\
\text { tData missing for } 6 \text { patients. } \\
\text { †Percentage of patients correctly identified by FPs as experiencing excessive substance use (patient's self-report in baseline } \\
\text { survey used as reference standard). } \\
\text { SIncludes } 4 \text { patients who were known substance users and were thus not formally screened. }\end{array}$} \\
\hline
\end{tabular}

cence. Further research on interventions with a stronger emphasis on multisectoral collaborations, effective screening and longer follow-up may provide more guidance. Further studies should also examine the extent to which a disapproving societal or family environment can modify the effect of brief interventions provided in the clinical setting. ${ }^{44}$

\section{Conclusion}

Our study showed that training family physicians to deliver a brief intervention to address excessive substance use among youth and young adults was not effective in reducing binge drinking and excessive cannabis use in this patient population.

\section{References}

1. Catalano RF, Fagan AA, Gavin LE, et al. Worldwide application of prevention science in adolescent health. Lancet 2012;379: 1653-64.

2. Sawyer SM, Afifi RA, Bearinger LH, et al. Adolescence: a foundation for future health. Lancet 2012;379:1630-40.

3. Gore FM, Bloem PJ, Patton GC, et al. Global burden of disease in young people aged 10-24 years: a systematic analysis. Lancet 2011;377:2093-102.
4. Levy SJ, Kokotailo PK. Substance use screening, brief intervention, and referral to treatment for pediatricians. Pediatrics 2011; 128:e1330-40.

5. Winstock AR, Ford C, Witton J. Assessment and management of cannabis use disorders in primary care. BMJ 2010;340:c1571.

6. Degenhardt L, Hall W. Extent of illicit drug use and dependence, and their contribution to the global burden of disease. Lancet 2012; 379:55-70.

7. Patton GC, Coffey C, Lynskey MT, et al. Trajectories of adolescent alcohol and cannabis use into young adulthood. Addiction 2007; 102:607-15

8. Meier MH, Caspi A, Ambler A, et al. Persistent cannabis users show neuropsychological decline from childhood to midlife. Proc Natl Acad Sci U S A 2012;109:E2657-64.

9. McArdle P. Use and misuse of drugs and alcohol in adolescence. BMJ 2008;337:a306.

10. Andersson B, Hibell B, Beck F, et al. Alcohol and drug use among european 17-18 year old students. Data from the ESPAD project. Stockholm (Sweden): Swedish Council for Information on Alcohol and Other Drugs, Pompidou Group at the Council of Europe; 2007.

11. Bonomo Y, Coffey C, Wolfe R, et al. Adverse outcomes of alcohol use in adolescents. Addiction 2001:96:1485-96.

12. Viner RM, Taylor B. Adult outcomes of binge drinking in adolescence: findings from a UK national birth cohort. J Epidemiol Community Health 2007;61:902-7.

13. Coffey C, Carlin JB, Lynskey M, et al. Adolescent precursors of cannabis dependence: findings from the Victorian Adolescent Health Cohort Study. Br J Psychiatry 2003;182:330-6.

14. US Centers for Disease Control and Prevention. Vital signs: binge drinking prevalence, frequency, and intensity among adults - United States, 2010. MMWR Morb Mortal Wkly Rep 2012;61:14-9. 
15. Currie C, Zanotti C, Morgan A, et al., editors. Social determinants of health and well-being among young people. Health Behaviour in School-aged Children (HBSC) study: international report from the 2009/2010 survey. Copenhagen (Denmark): WHO Regional Office for Europe; 2012.

16. Toumbourou JW, Stockwell T, Neighbors C, et al. Interventions to reduce harm associated with adolescent substance use. Lance 2007;369:1391-401.

17. Haller DM, Michaud PA, Suris JC, et al. Opportunities for prevention in primary care in a country with universal insurance coverage. J Adolesc Health 2008;43:517-9.

18. Tylee A, Haller DM, Graham T, et al. Youth-friendly primarycare services: How are we doing and what more needs to be done? Lancet 2007;369:1565-73

19. Bertholet N, Daeppen JB, Wietlisbach V, et al. Reduction of alcohol consumption by brief alcohol intervention in primary care: systematic review and meta-analysis. Arch Intern Med 2005; 165:986-95

20. Kaner EF, Dickinson HO, Beyer F, et al. The effectiveness of brief alcohol interventions in primary care settings: a systematic review. Drug Alcohol Rev 2009;28:301-23.

21. Whitlock EP, Polen MR, Green CA, et al. Behavioral counseling interventions in primary care to reduce risky/harmful alcohol use by adults: a summary of the evidence for the U.S. Preventive Services Task Force. Ann Intern Med 2004;140:557-68.

22. Moyer A, Finney JW, Swearingen CE, et al. Brief interventions for alcohol problems: a meta-analytic review of controlled investigations in treatment-seeking and non-treatment-seeking populations. Addiction 2002;97:279-92.

23. Wachtel T, Staniford M. The effectiveness of brief interventions in the clinical setting in reducing alcohol misuse and binge drinking in adolescents: a critical review of the literature. $J$ Clin Nurs 2010;19:605-20.

24. Boekeloo BO, Jerry J, Lee-Ougo WI, et al. Randomized trial of brief office-based interventions to reduce adolescent alcohol use. Arch Pediatr Adolesc Med 2004;158:635-42.

25. Sanci L, Coffey C, Patton G, et al. Sustainability of change with quality general practitioner education in adolescent health: a 5year follow-up. Med Educ 2005;39:557-60.

26. Sanci LA, Coffey CM, Veit FC, et al. Evaluation of the effectiveness of an educational intervention for general practitioners in adolescent health care: randomised controlled trial. BMJ 2000; 320:224-30.

27. Harris SK, Csemy L, Sherritt L, et al. Computer-facilitated substance use screening and brief advice for teens in primary care: an international trial. Pediatrics 2012;129:1072-82.

28. De Micheli D, Fisberg M, Formigoni ML. Study on the effectiveness of brief intervention for alcohol and other drug use directed to adolescents in a primary health care unit [article in Portuguese]. Rev Assoc Med Bras 2004;50:305-13.

29. Saitz R, Alford DP, Bernstein J, et al. Screening and brief intervention for unhealthy drug use in primary care settings: randomized clinical trials are needed. J Addict Med 2010;4:123-30.

30. Haller DM, Meynard A, Lefebvre D, et al. Brief intervention addressing excessive cannabis use in young people consulting family practitioners: a pilot study. Br J Gen Pract 2009;59:166-72.

31. Sanci LA, Sawyer SM, Weller PJ, et al. Youth health research ethics: Time for a mature-minor clause? Med J Aust 2004;180: 336-8

32. Haller DM, Sanci LA, Patton GC, et al. Practical evidence in favour of mature-minor consent in primary care research. Med J Aust 2005;183:439.

33. Levy S, Sherritt L, Harris SK, et al. Test-retest reliability of adolescents' self-report of substance use. Alcohol Clin Exp Res 2004;28:1236-41.

34. DEP-ADO Detection of alcohol and drug problems in adolescents. Québec (QC): Recherche et intervention sur les substances psychoactives - Quebec; 2007.

35. Sanci L, Glover S, Coffey C. Adolescent health education programmes: theoretical principles in design and delivery. Ann Acad Med Singapore 2003;32:78-85.

36. Naar-King S, Suarez M. Motivational interviewing with adolescents and young adults. New York (NY): Guilford Press; 2011.

37. Marlow SP, Stoller JK. Smoking cessation. Respir Care 2003; 48:1238-54, discussion 54-6.

38. Goldstein MG, Whitlock EP, DePue J. Multiple behavioral risk factor interventions in primary care. Summary of research evidence. Am J Prev Med 2004;27(Suppl):61-79.

39. Smith PC, Schmidt SM, Allensworth-Davies D, et al. Primary care validation of a single-question alcohol screening test. J Gen Intern Med 2009;24:783-8.

40. Smith PC, Schmidt SM, Allensworth-Davies D, et al. A single- question screening test for drug use in primary care. Arch Intern Med 2010;170:1155-60.

41. Chen P. Jacobson KC. Developmental trajectories of substance use from early adolescence to young adulthood: gender and racial/ethnic differences. J Adolesc Health 2012;50:154-63.

42. Adams G, Gulliford MC, Ukoumunne OC, et al. Patterns of intra-cluster correlation from primary care research to inform study design and analysis. J Clin Epidemiol 2004;57:785-94.

43. McCambridge J, Kypri K. Can simply answering research questions change behaviour? Systematic review and meta analyses of brief alcohol intervention trials. PLOS ONE 2011;6:e23748.

44. Kuntsche E, Jordan MD. Adolescent alcohol and cannabis use in relation to peer and school factors. Results of multilevel analyses. Drug Alcohol Depend 2006;84:167-74.

Affiliations: Division of Primary Care (Haller), Faculty of Medicine, University of Geneva, Geneva, Switzerland; Adolescent and Young Adult Program (Haller, Meynard, Narring), Departments of Child and Adolescent Health, and of Community Medicine, Primary Care and Emergency Medicine, Geneva University Hospitals, Geneva, Switzerland; Department of General Practice (Haller), University of Melbourne, Parkville, Australia; National Institute for Health Research (NIHR) Collaboration for Leadership in Applied Health Research and Care in the South West Peninsula (Ukoumunne), University of Exeter Medical School, Exeter, Devon, UK; general practice (Lefebvre), Versoix, Switzerland; Dependencies Unit (Broers), Division of Primary Care, Department of Community Medicine, Primary Care and Emergency Medicine, Geneva University Hospitals, Geneva, Switzerland

Contributors: Dagmar Haller and Anne Meynard conceptualized and designed the study and trained participants in the intervention group. Dagmar Haller organized the collection of data and participated in the analysis and interpretation of the data. Anne Meynard recruited and trained the actors involved in the intervention and contributed to the interpretation of the data. Daniele Lefebvre, Françoise Narring and Barbara Broers contributed to the conceptualization of the study and the interpretation of the data. Obioha Ukoumunne contributed to the conceptualization and design of the study, and the analysis and interpretation of the data. All of the authors had full access to the data and participated in the decision to submit for publication. Dagmar Haller drafted the article, and Anne Meynard, Daniele Lefebvre, Obioha Ukoumunne, Françoise Narring and Barbara Broers revised the manuscript critically for important intellectual content. All of the authors approved the final version of the manuscript submitted for publication and are guarantors of the work.

Funding: This study was funded by the Safra Foundation and Geneva University Hospitals, Switzerland; the KätheZingg-Schwichtenberg Fund (grant no. KZS 08/08), Swiss Academy for Medical Sciences; and the Swiss Federal Office of Public Health.

Obioha Ukoumunne is supported by the NIHR Collaboration for Leadership in Applied Health Research and Care in the South West Peninsula, a collaboration between the University of Exeter, the University of Plymouth and the NIHR South West that is funded by the NIHR.

None of the funding bodies had any direct influence on the design, conduct or analysis of the study.

Acknowledgements: The authors thank Gwendolyn Thys, psychologist, for skillfully coordinating the study, Gaëtan Conti for his innovative and useful IT developments, the medical students who conducted the phone interviews with much enthusiasm and professionalism, the actors who brought "real-life" conditions to the educational sessions, and the participating family physicians and their practice staff and patients for their valuable contribution to the study. They also thank Professors Lena A. Sanci, George C. Patton, Susan M. Sawyer and Andre Tylee for their advice on the original protocol for this study. 